\title{
The Causes of Electricity Theft: An Econometric Analysis for the Case of Turkey
}

\author{
Asst. Prof. Dr. Çağlar Yurtseven (Bahçeşehir University, Turkey)
}

\begin{abstract}
Every year, especially in developing countries, electricity theft causes billions of dollars of loss. Since the consumers who pay their bills legally, bear the burden of this loss, it disturbs the social justice. In addition by affecting the investment decisions, it distorts the economic growth hence the future of the nations as well. Authorities try to prevent electricity theft with different engineering techniques and devices designed especially for detecting purposes. However, there are ways to prevent this behavior before it took place. For this reason, energy theft equation is estimated with different techniques to understand the socio-economic background of this illegal behavior. Education, income and political ideologies are found to be the important electricity theft determinants. Policy suggestions, to prevent this illegal behavior before it took place, are discussed.
\end{abstract}

Full paper not published upon author's request. 